\title{
Structural Safety Assessment of Existing Multiarch Tunnel: A Case Study
}

\author{
Jinxing Lai, ${ }^{1}$ Junling Qiu, ${ }^{1}$ Haobo Fan, ${ }^{1,2}$ Jianxun Chen, ${ }^{1}$ Zhinan Hu, ${ }^{3}$ \\ Qian Zhang, ${ }^{3}$ and Junbao Wang ${ }^{4}$ \\ ${ }^{1}$ School of Highway, Chang'an University, Xian 710064, China \\ ${ }^{2}$ China Railway Eryuan Engineering Group Co. Ltd., Chengdu 610031, China \\ ${ }^{3}$ School of Civil Engineering, Shijiazhuang Tiedao University, Shijiazhuang 050043, China \\ ${ }^{4}$ School of Civil Engineering, Xian University of Architecture and Technology, Xian 710055, China
}

Correspondence should be addressed to Junling Qiu; 870133597@qq.com and Haobo Fan; 739512276@qq.com

Received 11 September 2016; Accepted 8 March 2017; Published 29 March 2017

Academic Editor: Carlo Santulli

Copyright (C) 2017 Jinxing Lai et al. This is an open access article distributed under the Creative Commons Attribution License, which permits unrestricted use, distribution, and reproduction in any medium, provided the original work is properly cited.

\begin{abstract}
Structural health assessment is one of the key activities in maintaining the performance of a tunnel during its service life. Due to the development of modern detection technology, comprehensive structural health assessment system is being established for operating tunnels. To evaluate the actual operational state of Shitigou tunnel, overall detection of the liner crack, tunnel seepage, and liner void was conducted by employing the modern detection technology, such as crack width monitoring technology, concrete strength monitoring technology, and electromagnetic wave nondestructive monitoring technology. Through the statistical analysis of the detection results, the distribution characteristic, development law, and damage grade of structural defects were obtained. Tunnel liner cracks are mainly located on the middle wall; serious water leakage is encountered on the side wall, middle wall, and vault; the strength of foundation and liner structure of left tunnel does not meet the design requirement; the liner voids are mostly located at the tunnel entrance section, especially, on the tunnel vault; and the proportion of influence factors of structural defects should be considered. The research results presented for this study can serve as references for effective design and health assessment of existing multiarch tunnel projects.
\end{abstract}

\section{Introduction}

An increasing number of tunnels are constructed in disadvantageous environments such as unfavorable geological structures, environments with high in situ stress, and shallow overburden areas [1-3]. Given the circumstances the structure of a tunnel usually suffers attacks from mechanical, physical, and even chemical actions [4]. The highly static indeterminate characteristics of a liner structure cause tunnels to change, frequently resulting in anomalies, such as liner crack, liner void, liner deterioration, and water leakage, with wide-ranging configurations in liner structures $[5,6]$. Investigation on some tunnel defects shows that $70 \%$ of tunnels have liner damage defects, accounting for about $40 \%$ of all tunnel defects. Liner concrete spalling can induce different damage to the entire tunnel structure and lower its reliability. Notably, water leakage will cause liner cracking and accelerate the preexisting crack extension, which damages the liner structure further [7]. Once a tunnel is opened, routine health inspections are necessary to ensure tunnel serviceability and user safety. Consequently, knowing when and where structural anomalies develop is important for tunnel health inspections, especially for diagnosis of tunnel serviceability and necessity of subsequent detailed inspections and monitoring, as shown in Figure 1. More specifically, the real-time data of service states can be collected by employing modern detection technology, which may be of help in understanding structure operational performance, and timely taking effective restoration measures [8-11].

Since the 1980s, with the wide application of probability theory and mathematical statistics in structural engineering, the structural failure probability was proposed to define 


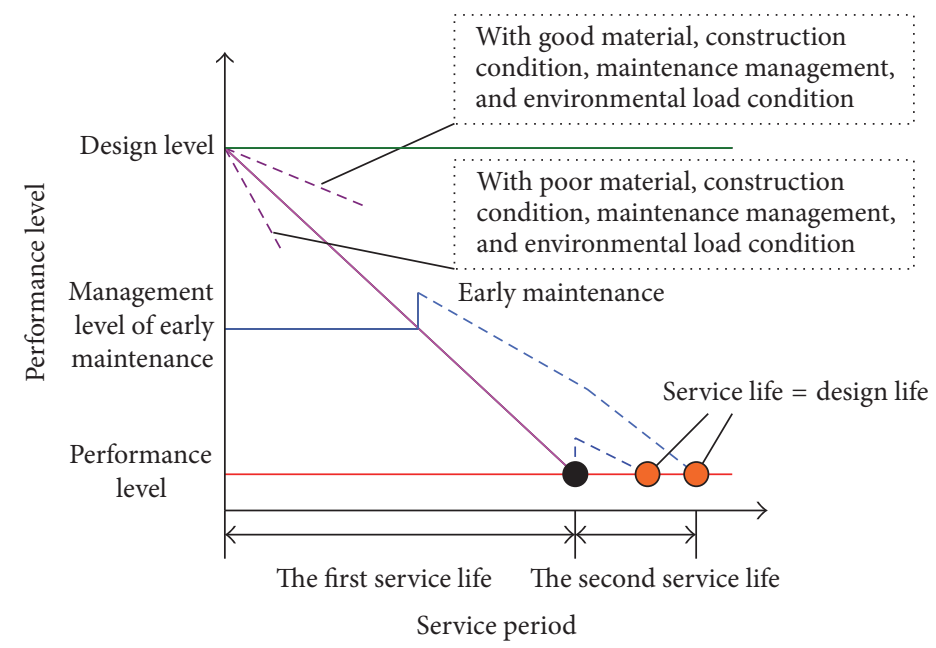

Figure 1: Structure deterioration characteristic.

the structural reliability $[12,13]$. For the structural health assessment of operating tunnels, to find out its exact service condition and to check the deviation from its design assumptions are two important aspects. Li et al. [14] performed the stability assessment of a loss tunnel through the established displacement prediction system. To scientifically evaluate the tunnel diseases, such as liner crack, water leakage, liner spalling, liner deterioration, liner deformation, and frost damage, the comprehensive analyses on the inspection results were conducted by Luo and Xia [15]. Zhou et al. [16] proposed a structural health assessment method to determine the tunnel structure's global stiffness based on torsional wave speed, which evaluated the tunnel's structural service states further. Based on simulated structural vibration data, Feng et al. [17] applied cross correlation analysis to perform structural damage detection and localization. Additionally, nondestructive testing approaches, including ground penetrating radar (GPR), ultrasonic wave, electromagnetic radiation, and acoustic emission, are usually employed to detect the location and potential harm of hidden defects, such as void, delaminating behind coating, thickness of concrete cover, or corrosive reinforcing bars [18-21]. In this sense, a number of new research projects have been funded to improve the damage detection methods including the use of innovative signal processing, new sensors, and control theory [22]. Based on the ISTIMES project funded by the European Commission, Proto et al. [23] presented the preliminary results arising from the GPR and infrared thermographic measurements conducted on the Musmeci Bridge in Potenza, located in a highly seismic area of the Apennine chain (Southern Italy). Through ultrasonic and boring core sampling, Nie and Lai $[24,25]$ investigated the crack and water leakage of a tunnel and detected the strength and thickness of liner structure as well as the backfill tightness of tunnel vault. To obtain the operating state of a tunnel in the cold plateau region, Kang and Yan $[26,27]$ used the GPR to detect the tunnel disease and assessed the integral safety of liner structure. In situ investigation of the liner cracks was conducted by Ye et al. [28] to obtain the statistics, which includes the number, length, inclination, width, and depth of typical cracks. At present, according to the adaptive neurofuzzy inference system (ANFIS) and neural network, based on the index of tunnel defects, the health assessment management system of tunnel structure is gradually established [29, 30]. Due to the development of modern monitoring technology, comprehensive structural health assessment is being established for the operating tunnels.

China is now enjoying a boom in tunnel traffic construction; evidently, the detection and health assessment of highway tunnel become more and more important [31, 32], especially the health assessment of multiarch tunnels. To investigate the liner cracks, tunnel seepage, and liner voids developed around an existing multiarch tunnel, the health assessment was performed by employing the in situ detection technology. Meanwhile, the change of operating condition as well as the technical state evaluation for the tunnel structure could be obtained.

\section{Project Overview}

As a multiarch tunnel, Shitigou tunnel, with a total length of $2 \times 320=640 \mathrm{~m}$, was opened in 2002 . The mileage of tunnel is $\mathrm{K} 239+895-\mathrm{K} 240+215$, and the distance between the two tunnels is $10.75 \mathrm{~m}$. The rock mass grade of Shitigou tunnel is IV and many ponds which are higher than the design elevation of pavement locate near the tunnel axis. The groundwater is mainly of bedrock fissure water, which is hosted in silty mudstone and shaly sand. The source for water supply mainly consists of meteoric water and surface water. After several years of operation, through preliminary examination, many defects especially liner void, liner crack, and water leakage have been found in the Shitigou tunnel, where the soil stability is poor and the geological condition is complex. Accordingly, the systematic structural health assessment for the tunnel should be performed, and corresponding treatment measures need to be taken.

Generally, as the core content of the tunnel structure health inspection, data collecting is an important part of 


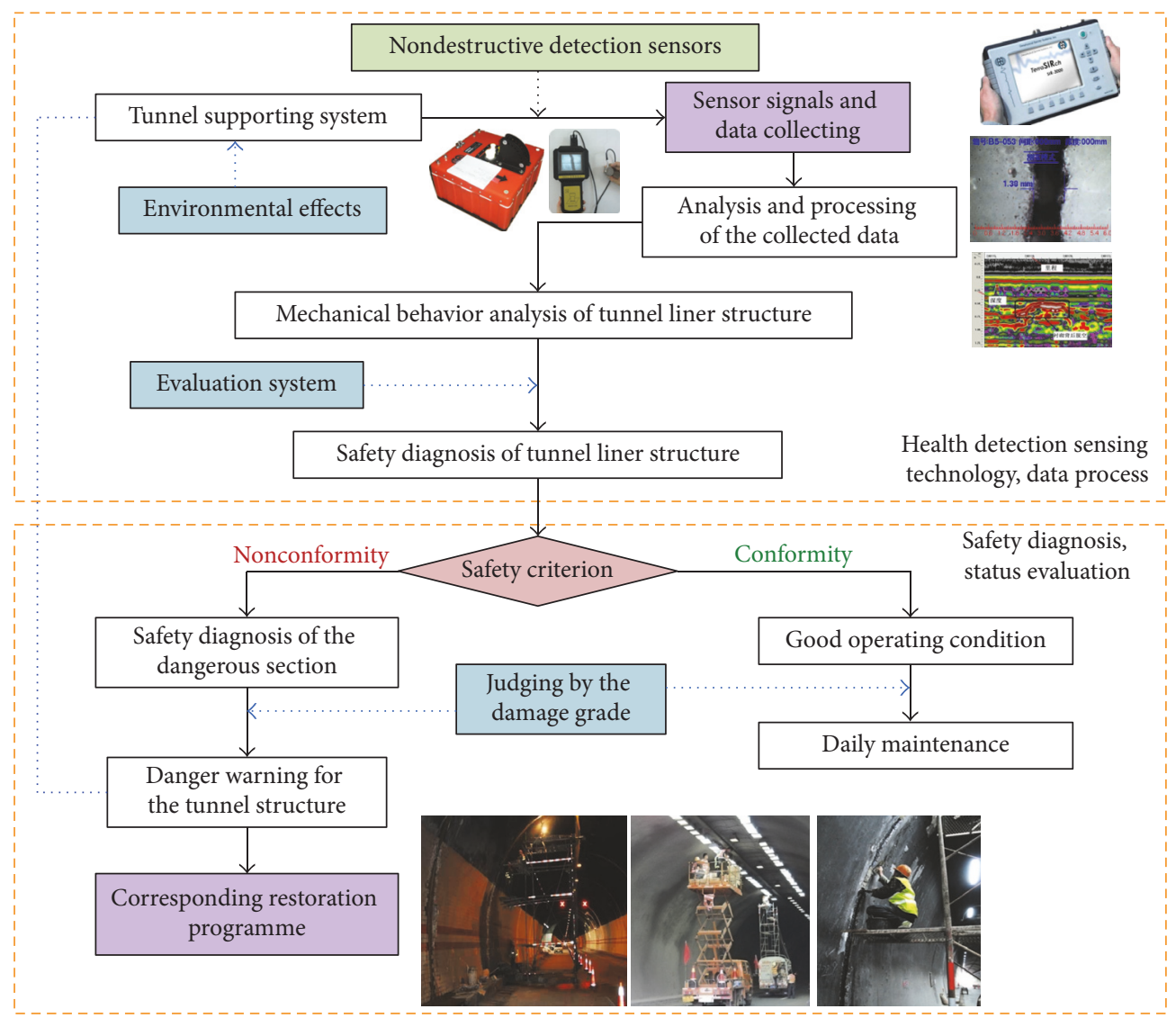

FIGURE 2: Safety assessment system of the tunnel structure.

the detection system. Through the combined application of the modern detection technology in the operating multiarch tunnel, as shown in Figure 2, several problems could be solved: (1) confirming the actual performance of the multiarch tunnel; (2) mastering the safety degree of the tunnel structure; (3) providing the essential service for the comprehensive management system of the tunnel maintenance; (4) considering the influence factors of structural defects, proposing corresponding restoration programme.

\section{Structural Safety Assessment of Shitigou Tunnel}

3.1. Liner Crack Condition Assessment. The liner crack not only does harm to the stability and durability of tunnel structure but also directly influences the safety of vehicles and pedestrians in the tunnel [33-35]. Measuring tape and crack width measuring instrument were adopted to detect the length and width of liner cracks, as shown in Figure 3. DJCK-2 intelligent crack width measuring instrument was adopted, and the widest part of the liner crack was chosen as the measuring position. During monitoring, cracks were scanned through the microprobe, and then the liner width was obtained from the instrument screen with the precision of $0.01 \mathrm{~mm}$ [36].

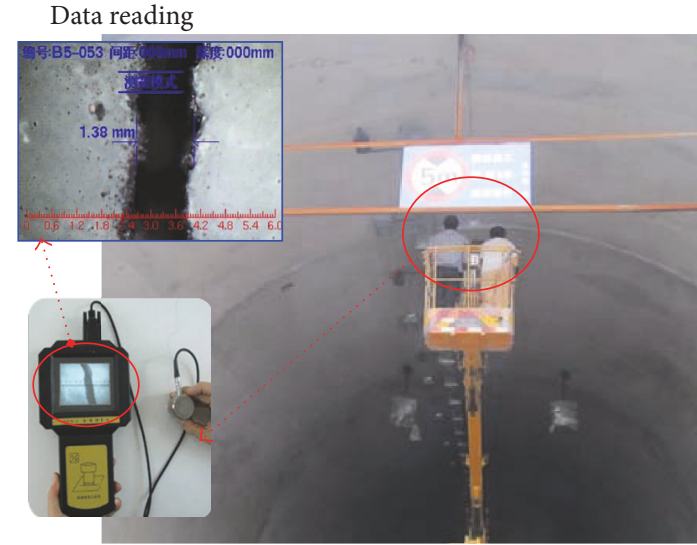

Intelligent crack width measuring instrument (DJCK-2)

FIgURE 3: Liner crack width detection for Shitigou tunnel.

(1) Assessment Criteria (Technical Specifications of Maintenance for Highway Tunnel JTG H12-2015). Generally, considering the development of cracks and its influence on the liner structure, four assessment grades (B, 1A, 2A, and $3 \mathrm{~A}$ ) and assessment criteria for structural damage have been judged 
TABLE 1: Assessment criteria for liner crack.

\begin{tabular}{lccccc}
\hline \multirow{2}{*}{ Structure } & \multicolumn{3}{c}{ Crack width $b(\mathrm{~mm})$} & \multicolumn{3}{c}{ Crack length $l(\mathrm{~m})$} & Grade \\
& $b>3$ & $b \leq 3$ & $l>5$ & $l \leq 5$ & \\
\hline \multirow{4}{*}{ Liner } & $\sqrt{ }$ & & $\sqrt{ }$ & & $2 \mathrm{~A} / 3 \mathrm{~A}$ \\
& $\sqrt{ }$ & & & $\sqrt{ }$ & $\mathrm{A} / 2 \mathrm{~A}$ \\
& & $\sqrt{ }$ & $\sqrt{ }$ & & $1 \mathrm{~A}$ \\
& & $\sqrt{ }$ & & $\sqrt{ }$ & $1 \mathrm{~A}$ \\
\hline
\end{tabular}

based on the crack size [37]. And the assessment criteria for liner cracks are presented in Table 1.

(2) Assessment Results Analysis. There were 56 cracks in total on the right tunnel, which were, respectively, located in left liner, right liner, and tunnel arch. The crack width is mainly $1 \mathrm{~mm}<b \leq 2 \mathrm{~mm}$, accounting for 62 percent of the total cracks (Figure 4). Meanwhile, there were 51 cracks in total on the left tunnel, which were, respectively, distributed in left liner, right liner, and tunnel arch. 21 cracks with the width of $0 \mathrm{~mm}<b \leq 1 \mathrm{~mm}$ accounted for 41 percent of the total cracks. 22 cracks with the width of $1 \mathrm{~mm}<b \leq 2 \mathrm{~mm}$ accounted for 43 percent of the total cracks. Table 2 illustrates the spatial distribution of cracks with different extension directions.

The distribution of cracks was scattered on the side wall of right tunnel, and most cracks were less than $1 \mathrm{~mm}$, without development trend. The distribution of cracks on the middle wall was relatively dense, and many cracks were developing gradually; in particular, the cracks located on the liner surface $170 \mathrm{~m}$ away from the tunnel entrance had reached $3 \mathrm{~mm}$. The cracks on tunnel vault were developing along the direction of construction joints. Accordingly, from the inspection data, the criteria grade of structural damage for the right tunnel is $1 \mathrm{~A}$; that is, the structural damage may endanger the safety of pedestrians and vehicles, for which the corresponding measures shall be taken. The distribution of cracks was sporadic on the side wall of right tunnel, and the distribution of cracks on the middle wall was relatively dense; in particular, the cracks located on the liner surface $8 \mathrm{~m}$ away from the tunnel entrance had reached $3.2 \mathrm{~mm}$. Also, the cracks on tunnel vault were developing along the direction of construction joints. Accordingly, it can be determined that the criteria grade of structural damage for the left tunnel is 1A.

3.2. Tunnel Seepage Condition Assessment. Generally, the groundwater around the tunnel will flow inside the tunnel in a concentrated manner. In case of the poor drainage measures or the damaged waterproof layers, the water leakage damage would be caused, inducing liner peeling-off and the tunnel durability [38]. Furthermore, with a great threat to traffic safety, the leakage-induced road waterlogging will reduce the adhesive force between vehicle and pavement in tunnels [39].

(1) Assessment Criteria (Technical Specifications of Maintenance for Highway Tunnel JTG H12-2015). Usually, the tunnel seepage occurs simultaneously with the liner cracks. Therefore, the water leakage, the development of cracks near the

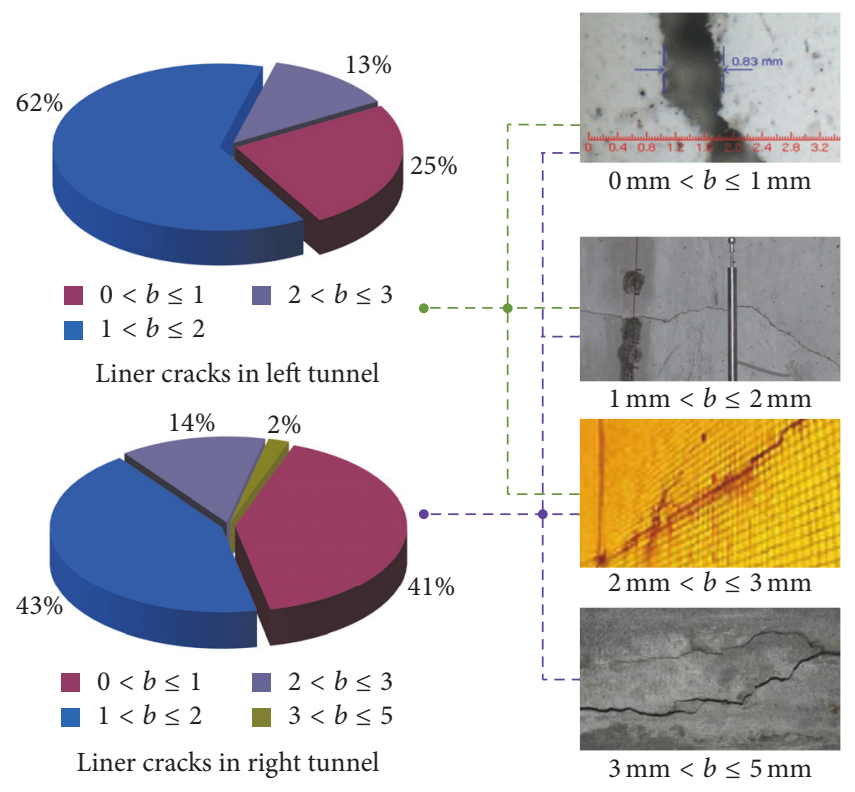

FIgURE 4: Statistics of liner cracks in Shitigou tunnel.

seepage position, and the sandy soil carried by water leakage should be thoroughly taken into account for the qualitative assessment criteria. And then the tunnel seepage condition is determined into five grades $(\mathrm{S}, \mathrm{B}, 1 \mathrm{~A}, 2 \mathrm{~A}$, and $3 \mathrm{~A})$ according to the severity of the damage and the assessment criteria for seepage. Specifically, the severity of tunnel seepage can be determined according to the investigation form (Table 3 ).

(2) Assessment Results Analysis. According to the inspection results, it could be seen that serious water leakage was encountered on the side wall, middle wall, and vault of the right tunnel, especially on site $42 \mathrm{~m}$ away from the tunnel entrance. Accordingly, it can be determined that the criteria grade of tunnel seepage for the right tunnel is $1 \mathrm{~A}$; that is, the large water seepage that appeared near liner cracks may affect the traffic safety in the near future, for which the corresponding measures shall be taken. Meanwhile, for the left tunnel, the serious water leakage was also encountered on the side wall, middle wall, and vault. Specifically, the drip and leakage with large area were found on the middle wall $55 \mathrm{~m}-59 \mathrm{~m}$ away from the tunnel entrance, as well as on the middle wall $40 \mathrm{~m}$ away from the tunnel entrance, as shown in Figure 5. Also, the vault $28 \mathrm{~m}$ away from the tunnel entrance had a water dripping area (Figure 6). Accordingly, the criteria grade of tunnel seepage for the left tunnel is 1A.

\subsection{Structural Strength and Thickness Assessment}

(1) Detection Point Arrangement. To accurately ascertain the construction quality of tunnel supporting structure, the sampling assessment was conducted for tunnel liner, pavement, and foundation employing the boring core sampling method [40]. Figure 7 shows the detection point layout of the boring core sample. The boring core sampling on pavement and liner are, respectively, shown in Figure 8. 
TABLE 2: Spatial distribution statistics of cracks with different extension directions.

\begin{tabular}{lccc}
\hline Type of crack & Proportion of total cracks (\%) & Crack location & Proportion of cracks (\%) \\
\hline & & Vault & 21.8 \\
Annular crack & 55.3 & Hance & 37.6 \\
& & Side wall & 40.6 \\
\hline & & Vault & 69.4 \\
Longitudinal crack & 35.9 & Hance & 19.8 \\
& & Side wall & 10.8 \\
\hline Inclined crack & 8.8 & &
\end{tabular}

TABLE 3: Investigation on the tunnel seepage.

\begin{tabular}{|c|c|c|c|c|c|c|c|c|}
\hline \multirow{2}{*}{ Structure } & \multirow{2}{*}{ Main abnormal phenomena } & \multicolumn{4}{|c|}{ Degree of leakage } & \multicolumn{2}{|c|}{ Affecting traffic safety } & \multirow{2}{*}{ Grade } \\
\hline & & $\mathrm{I}$ & II & III & IV & $\mathrm{Y}$ & $\mathrm{N}$ & \\
\hline \multirow{4}{*}{ Arch } & \multirow{4}{*}{ Leakage } & $\sqrt{ }$ & \multirow{4}{*}{$\sqrt{ }$} & \multirow{4}{*}{$\sqrt{ }$} & & $\sqrt{ }$ & & $3 \mathrm{~A}$ \\
\hline & & & & & & $\sqrt{ }$ & & $2 \mathrm{~A}$ \\
\hline & & & & & & $\sqrt{ }$ & & $1 \mathrm{~A}$ \\
\hline & & & & & $\sqrt{ }$ & & $\sqrt{ }$ & $\mathrm{B}$ \\
\hline \multirow{4}{*}{ Side wall } & \multirow{4}{*}{ Leakage } & $\sqrt{ }$ & \multirow{4}{*}{$\sqrt{ }$} & & & $\sqrt{ }$ & & $3 \mathrm{~A}$ \\
\hline & & & & & & $\sqrt{ }$ & & $2 \mathrm{~A}$ \\
\hline & & & & $\sqrt{ }$ & & $\sqrt{ }$ & & $1 \mathrm{~A}$ \\
\hline & & & & & $\sqrt{ }$ & & $\sqrt{ }$ & $\mathrm{B}$ \\
\hline \multirow{4}{*}{ Pavement } & \multirow{2}{*}{ Sandy soil outflow } & & & & & $\sqrt{ }$ & \multirow{3}{*}{$\sqrt{ }$} & $2 \mathrm{~A} / 3 \mathrm{~A}$ \\
\hline & & & & & & & & B \\
\hline & \multirow{2}{*}{ Waterlogging } & & & & & $\sqrt{ }$ & & $2 \mathrm{~A} / 3 \mathrm{~A}$ \\
\hline & & & & & & & $\sqrt{ }$ & B \\
\hline
\end{tabular}

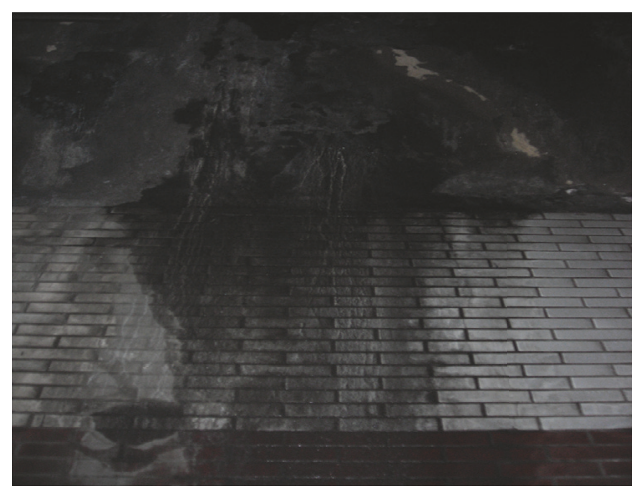

FIGURE 5: Leakage on middle wall of left tunnel.

TABLE 4: Concrete strength grade.

\begin{tabular}{lccccc}
\hline Type & C15 & C20 & C25 & C30 & C35 \\
\hline Axial compressive strength $f_{\text {cd }}$ & 7.5 & 10 & 12.5 & 15 & 16.1 \\
Flexural compressive strength $f_{\text {cmd }}$ & 8.5 & 11 & 13.5 & 16.5 & 17.7 \\
Axial tensile strength $f_{\text {ctd }}$ & 0.93 & 1.13 & 1.33 & 1.47 & 1.52 \\
\hline
\end{tabular}

(2) Assessment Criteria (Technical Specifications of Maintenance for Highway Tunnel JTG H12-2015). The assessment criteria for concrete strength are shown in Table 4.

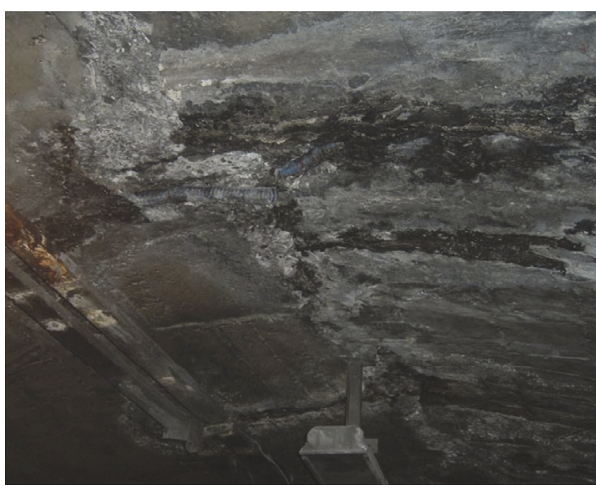

FIGURE 6: Leakage on vault of left tunnel.

(3) Assessment Results Analysis. The detection results of structural strength and thickness are shown in Figures 9 and 10 , respectively. The concrete with intensive grade of C25 was used for tunnel foundation and liner; meanwhile, the C10 concrete was used for tunnel pavement base, and the C35 concrete was used for tunnel pavement surface. Figure 9 shows that the strength of pavement and liner structure of right tunnel meets the design requirement. The minimum axial compressive strength of sampling points on the left tunnel foundation and liner structure, however, is $10.3 \mathrm{MPa}$, which does not meet the design requirement. The tunnel pavement has the design thickness of $45 \mathrm{~cm}$, and the total 


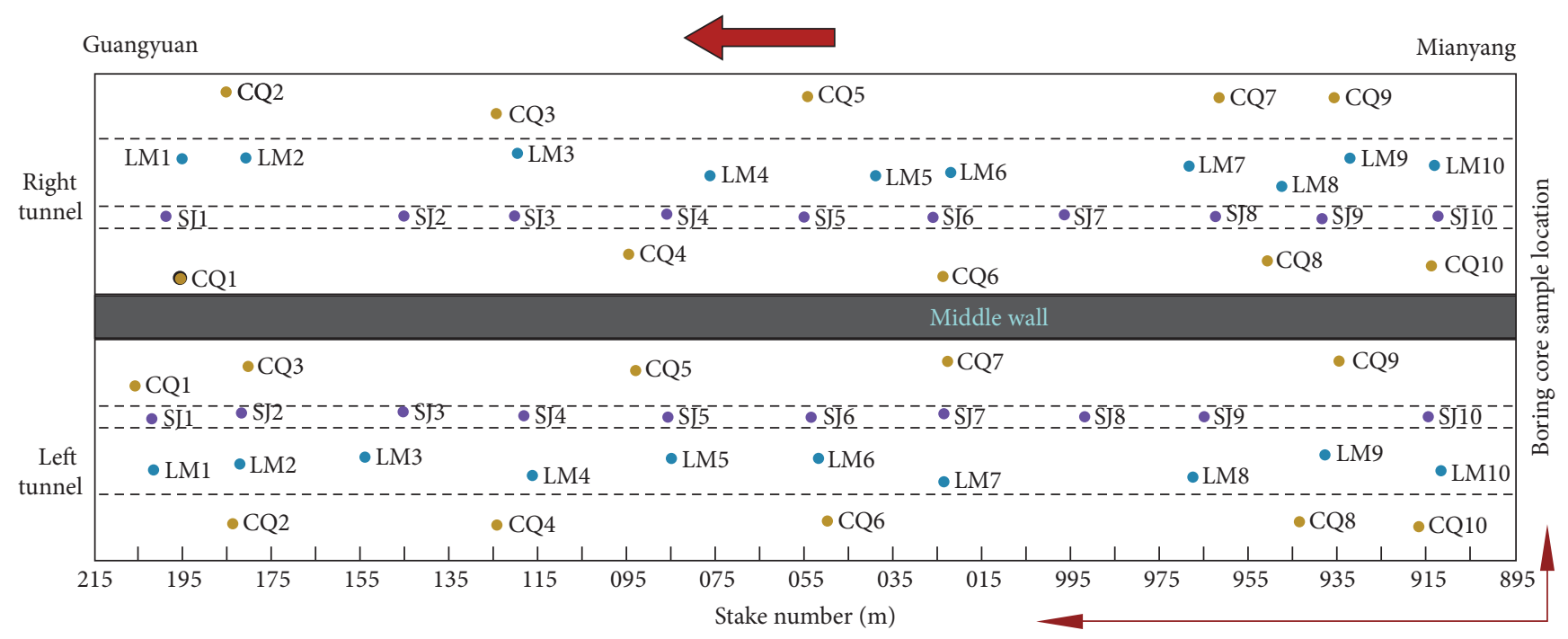

- CQ-liner

- LM-pavement

- SJ-foundation

FIGURE 7: Detection point layout of the boring core sample.

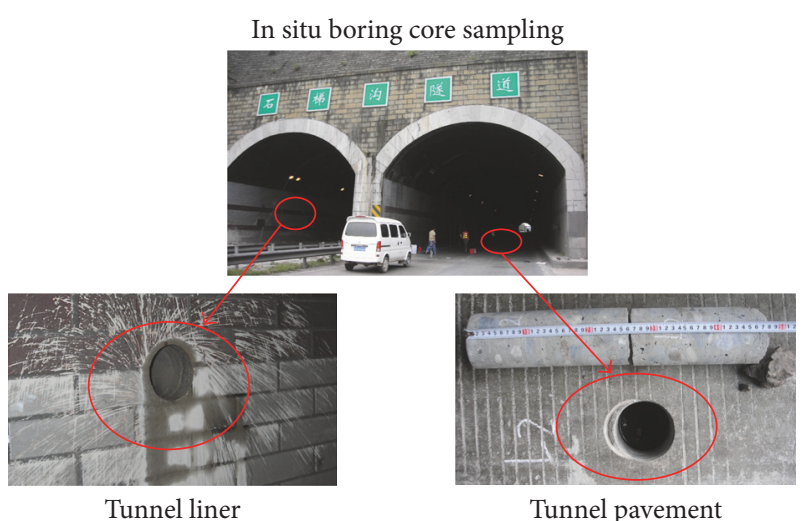

FIGURE 8: Boring core sampling on the tunnel structure.

design thickness of primary support and secondary liner is $80 \mathrm{~cm}$. From Figure 10, the thicknesses of tunnel foundation, liner, and pavement of the sampling points all satisfy the design requirements. Based on the observation of boring core samples on the side wall, middle wall, and pavement base, the base backfill was relatively compacted, and the softening phenomena appeared at the entrance and exit section of Shitigou tunnel due to long-term influence of groundwater.

\subsection{Liner Void Condition Assessment}

(1) Detecting Instrument and Arrangement. Ground penetrating radar (SIR-3000) with antenna frequency of $400 \mathrm{MHz}$ produced by Geophysical Survey Systems, Inc., was used for liner void detection in Shitigou tunnel. The radar consists of host, antenna, corresponding software, and so forth [41]. According to the propagation characteristics of the electromagnetic wave in lossy media, GPR launches high-frequency

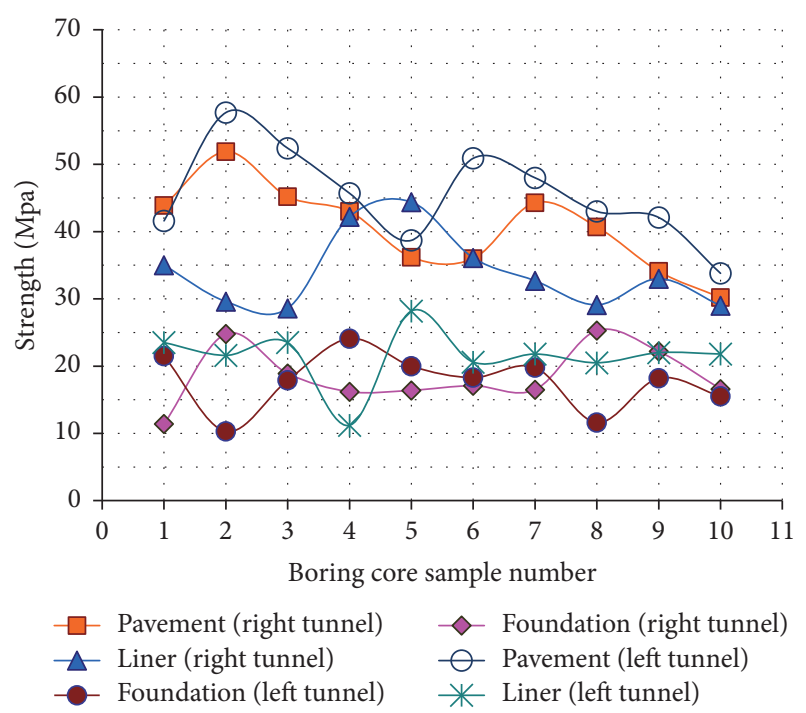

FIGURE 9: Structural strength detection results.

impulse electromagnetic waves to the measured media by transmitting antenna and then receives the backward electromagnetic waves by the receiving antenna, which can detect and recognize the liner voids with the high accuracy [42]. The reflection coefficient mainly depends on the dielectric constant of the measured media [43-46]. Considering the site condition in Shitigou tunnel, eight detection lines were laid on the tunnel hance (about $6 \mathrm{~m}$ away from the pavement), side wall (about $1.36 \mathrm{~m}$ away from the pavement), and vault, of which the detection lines of LZ-1, LZ-2, LZ-3, and LZ-4 were laid in left tunnel and the detection lines of LY-1, LY-2, LY-3, and LY-4 were laid in right tunnel. The detection line layout is shown in Figure 11. 


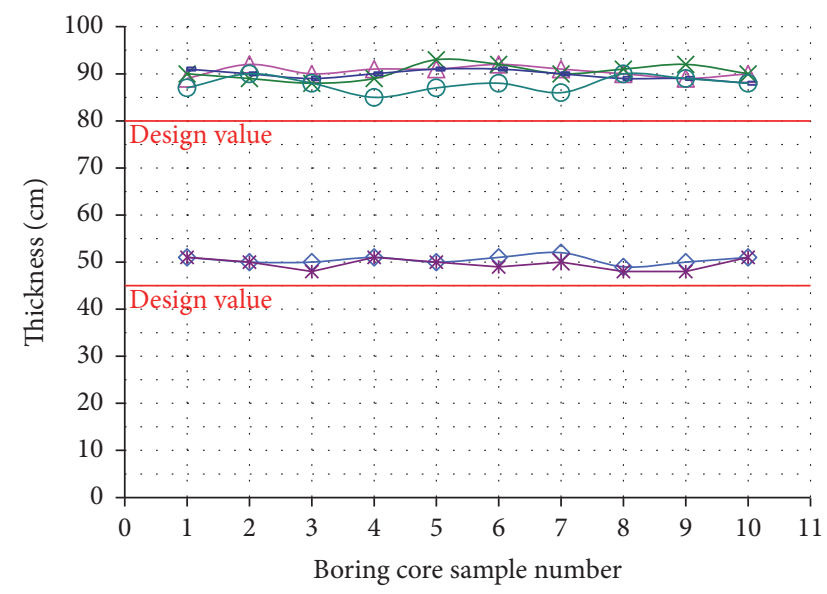

$$
\begin{array}{ll}
\diamond \text { Pavement (right tunnel) } & \triangle \text { Foundation (right tunnel) } \\
\star-\text { Liner (right tunnel) } & \because \text { Pavement (left tunnel) } \\
-- \text { Foundation (left tunnel) } & - \text { Liner (left tunnel) }
\end{array}
$$

Figure 10: Thickness detection results.

TABLE 5: Grade determination of void behind the liner.

\begin{tabular}{lcccc}
\hline \multirow{2}{*}{ Void location } & \multicolumn{4}{c}{ Void area size $(\mathrm{m})$} \\
& $<0.5$ & $0.5-1.0$ & $1.0-2.0$ & $>2.0$ \\
\hline Vault & $\mathrm{A}$ & $2 \mathrm{~A}$ & $3 \mathrm{~A}$ & $3 \mathrm{~A}$ \\
Hance & $\mathrm{A}$ & $2 \mathrm{~A}$ & $3 \mathrm{~A}$ & $3 \mathrm{~A}$ \\
Side wall & $\mathrm{A}$ & $2 \mathrm{~A}$ & $2 \mathrm{~A}$ & $3 \mathrm{~A}$ \\
\hline
\end{tabular}

(2) Assessment Criteria (Technical Specifications of Maintenance for Highway Tunnel JTG H12-2015). The influence of voids with different sizes in different locations on the tunnel stability is shown in Table 5.

(3) Assessment Results Analysis. Detection data were processed by corresponding data processing software, mainly including amplitude recovery, filtering, F-K filtering, and deconvolution processing. And the time profile with high signal-to-noise ratio (SNR) was obtained, which could improve the identification of useful signals. The time profile of radar can reflect the change of underground media veritably and comprehensively, ensuring the quality of detection data. Based on the detecting results, the liner voids with different sizes were determined in the eight detection lines and the typical oscillogram for liner voids is shown in Figure 12.

The detection range of the vault in right tunnel was YK240+116-YK240+119 (Figure 12). Discontinuous seismic event appeared in this section, and reflected waves with highenergy were formed owing to the large difference of dielectric properties between air and soil, which could accordingly determine the location and size of liner voids. The void area is about $3 \mathrm{~m}$ wide and $8 \mathrm{~cm}$ thick. Through the statistical analysis of void area in different detection lines, the void area layout can be identified in Figure 13.

The distributions of liner voids with different locations and different lengths are shown in Figures 14 and 15, respectively. From the aforementioned, the liner voids were mostly located at the tunnel entrance section, while relatively few voids were located at the middle section and exit section

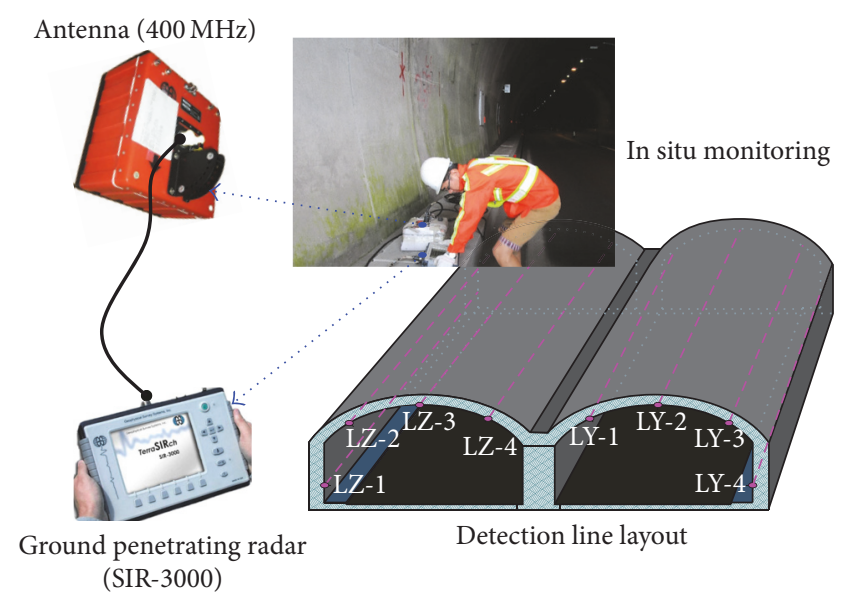

FIGURE 11: Detection line layout for voids behind the tunnel liner.

of the tunnel. Specifically, the voids were mainly located on the tunnel vault, and the void lengths on the vaults of left and right tunnels were $110.6 \mathrm{~m}$ and $91.2 \mathrm{~m}$, respectively, accounting for $34.6 \%$ and $28.5 \%$ of the tunnel length. Meanwhile, the void lengths on the side walls of left and right tunnels were $73 \mathrm{~m}$ and $41.3 \mathrm{~m}$, respectively, accounting for $22.8 \%$ and $12.9 \%$ of the tunnel length. Through contrastive analysis, the occurrence probability of void on the vault was the highest, while the occurrence probability of void on the hance was the lowest. With the increase of void length, the void frequency increased linearly when the void length was less than $5 \mathrm{~m}$. However, the void frequency decreased exponentially when the void length was more than $5 \mathrm{~m}$. The distribution law was similar to the Poisson distribution, which could provide references for the determination of the grouting holes and grouting amount. As a whole, the liner void damage is quite serious in Shitigou tunnel; therefore, the grouting reinforcement should be performed to the void sections.

\section{Preliminary Restoration Programme}

Based on the structural safety assessment results of Shitigou tunnel, the major restoration programme was proposed, as detailed in Table 6.

Additionally, the inducements for tunnel structural defects are the important basis for proposing the effective restoration programme. According to the statistics of detection data of tunnel structural defects in recent years, as well as the distribution characteristics of structural defects induced by different factors, the proportion of influence factors of structural defects is obtained, which plays a role in guiding the restoration design for later structural health assessment. Specifically, the unsymmetrical pressure and void behind liner and loosening load are the main influence factors for structural defects, which accounts for $15.1 \%, 12.3 \%$, and $10.9 \%$ of the influence factors, respectively (Figure 16).

\section{Concluding Remarks}

Through the combined application of the modern detection sensors in the operating multiarch tunnel, the structural 


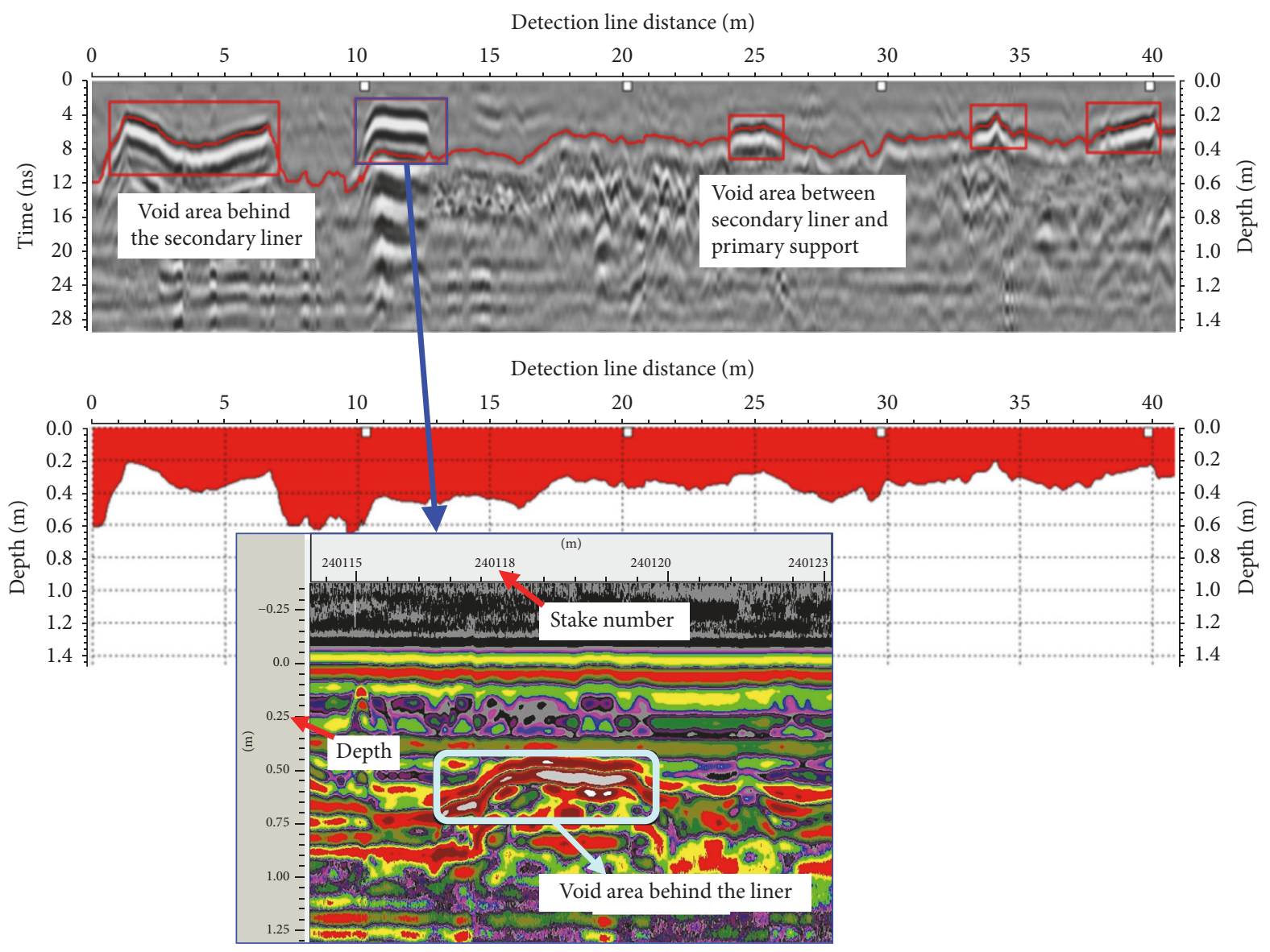

Figure 12: Typical oscillogram for liner voids (vault).

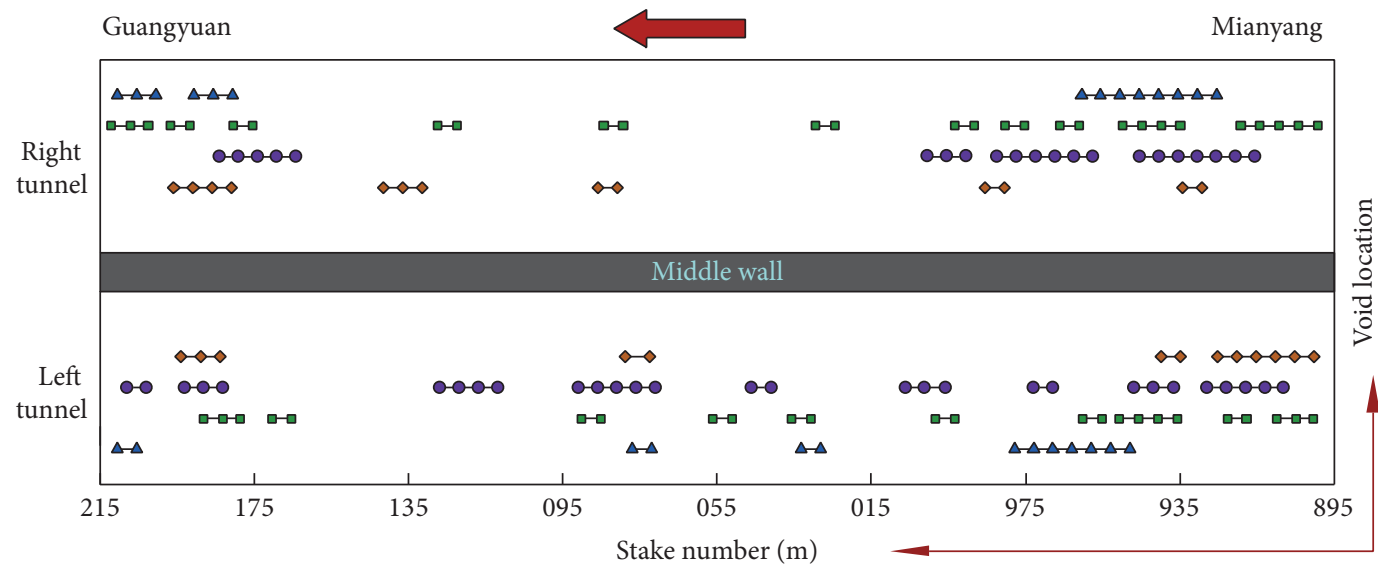

Right tunnel

$\triangle$ Side wall

$\rightarrow$ Right hance

$\rightarrow$ Vault

$\multimap$ Left hance

Left tunnel

$\triangle$ Side wall

$\rightarrow$ Left hance

$\rightarrow$ Vault

$\multimap$ Right hance

FIGURE 13: Void area layout. 
TABLE 6: Major restoration programme for structural defects of Shitigou tunnel.

\begin{tabular}{|c|c|c|}
\hline \multicolumn{2}{|l|}{ Type of defects } & Restoration programme \\
\hline \multicolumn{2}{|l|}{ Liner crack } & $\begin{array}{l}\text { A V-shaped groove } 5 \mathrm{~cm} \text { wide and } 3 \mathrm{~cm} \text { deep was made following the direction of crack, a hole } \\
\text { every } 0.5 \mathrm{~m} \text { at the junction of the groove edges was bored, and cement-water glass grout or epoxy } \\
\text { resin grout was infused at pressure of } 0.15-0.2 \mathrm{MPa} \text {. }\end{array}$ \\
\hline \multirow{2}{*}{$\begin{array}{l}\text { Tunnel } \\
\text { seepage }\end{array}$} & Side wall & $\begin{array}{l}\text { A small groove along the watered points was made and led to the permanent drainage system. The } \\
\text { size of the small groove section was } 5 \times 5 \mathrm{~cm} \text {. The surroundings of the small groove were smooth, } \\
\text { half PVC of } 50 \mathrm{~mm} \text { was reversed into the small groove, and plugging agent or epoxy resin mortar } \\
\text { was used to fill in the small groove. }\end{array}$ \\
\hline & Arch & $\begin{array}{l}\text { Grouting holes with spacing of } 1-2 \mathrm{~m} \text { and diameter of } 42 \mathrm{~mm} \text { were made, and then the grouting } \\
\text { pipe was laid. For the little water leakage, plugging agent or epoxy resin mortar could be infused } \\
\text { using a small grouter with the grouting pressure of } 0.2-0.4 \mathrm{MPa} \text {. For the great water leakage, } \\
\text { chemical grouting shall be employed. }\end{array}$ \\
\hline Liner void & & $\begin{array}{l}\text { The cement paste mixed liquor was used in grouting, consisting of } 80 \% \text { cement, } 20 \% \text { grade-II coal } \\
\text { ash, and aluminum powder expansive agent mixed with } 1 / 10000 \text { cement. The grouting pressure } \\
\text { shall be controlled within } 0.3-0.5 \mathrm{MPa} \text {. }\end{array}$ \\
\hline
\end{tabular}

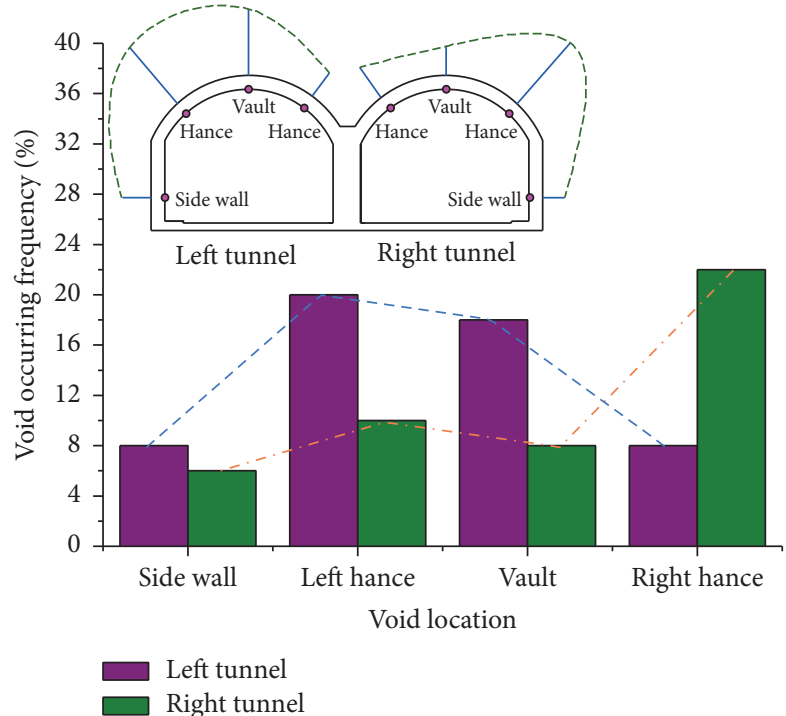

Figure 14: Distribution of liner voids with different locations.

safety assessment was performed accordingly, and the following conclusions are obtained:

(1) For the right tunnel, the crack width is mainly $1 \mathrm{~mm}<$ $b \leq 2 \mathrm{~mm}$, accounting for 62 percent of the total cracks. Meanwhile, for the left tunnel, 21 cracks with the width of $0 \mathrm{~mm}<b \leq 1 \mathrm{~mm}$ accounted for 41 percent of the total cracks. 22 cracks with the width of $1 \mathrm{~mm}<b \leq 2 \mathrm{~mm}$ accounted for 43 percent of the total cracks. Accordingly, from the inspection data, it can be determined that the criteria grade of liner crack damage is $1 \mathrm{~A}$, for which the corresponding grouting should be performed.

(2) Serious water leakage is encountered on the side wall, middle wall, and vault. There is a large seepage area on the wall, and the criteria grade of tunnel seepage is determined to be $1 \mathrm{~A}$. It is suggested that the area with serious seepage should be sealed by grouting,

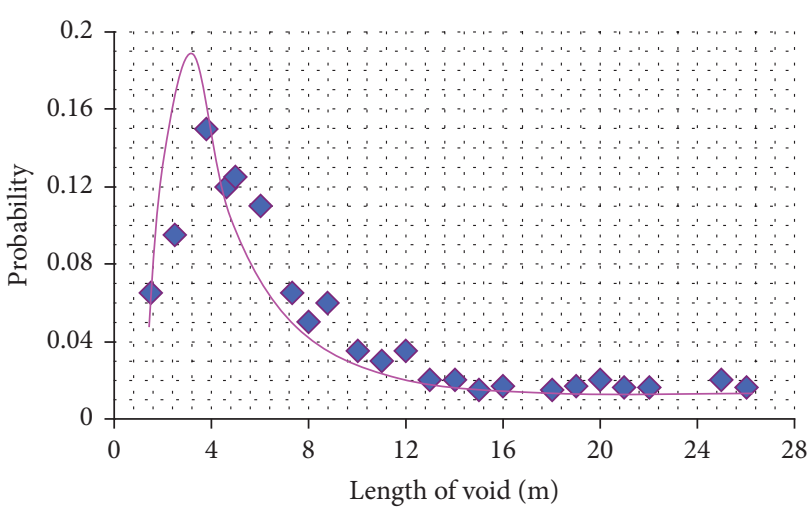

FIGURE 15: Length distribution of liner voids.
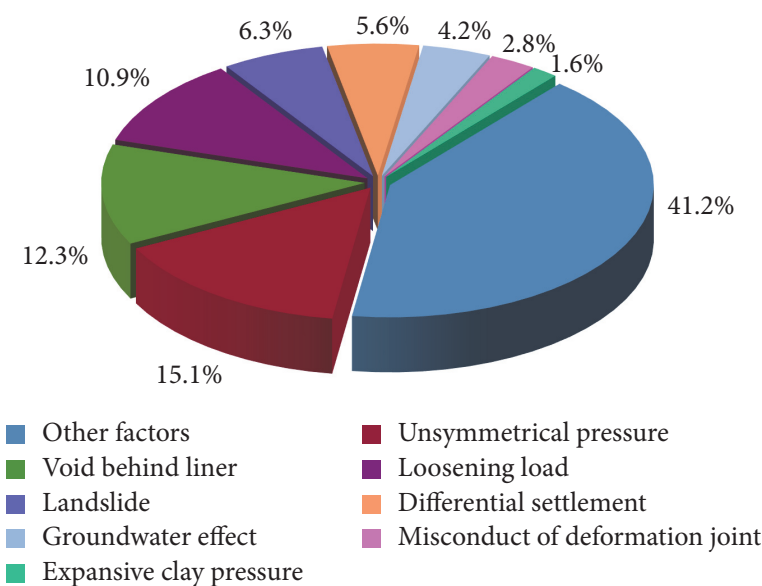

FIGURE 16: Proportion statistic of influence factors for structural defects.

and measures of interception and drainage prevention for surface water should be taken.

(3) The strength of pavement and liner structure of right tunnel meets the design requirement. The axial compressive strength of sampling points on foundation 
and liner structure of left tunnel does not meet the design requirement. Because of the long-term influence of groundwater, the softening phenomena appear at the entrance and exit section of the tunnel, for which the corresponding measures should be taken.

(4) The liner voids are mostly located at the tunnel entrance section, while relatively few voids are located at the middle section and exit section of the tunnel. Specifically, the voids are mainly located on the tunnel vault, and the void lengths on the vaults of left and right tunnels are $110.6 \mathrm{~m}$ and $91.2 \mathrm{~m}$, respectively, accounting for $34.6 \%$ and $28.5 \%$ of the tunnel length. The liner void damage is quite serious; therefore, it is suggested that the grouting reinforcement should be performed to the void sections.

(5) To propose the effective restoration programme for tunnel structural defects, scientific statistic analysis should be conducted to the detection and assessment results of the defects, such as the liner crack, tunnel seepage, and liner void. Additionally, the distribution characteristics of structural defects induced by different factors and the structural damage grade as well as the different inducements should also be considered.

\section{Conflicts of Interest}

The authors declare that there are no conflicts of interest regarding the publication of this paper.

\section{Acknowledgments}

This work is financially supported by the Special Fund for Basic Scientific Research of Central Colleges of Changan University (no. 310821172004, no. 310821153312, and no. 310821165011) and the Collaborative Innovation Project of Shaanxi Province (no. 2015XT-33).

\section{References}

[1] H. J. Liu, C. C. Xia, H. H. Zhu et al., "Studies on tunnel damage," Chinese Journal of Underground Space and Engineering, vol. 3, no. 5, pp. 947-953, 2007.

[2] F. Ye, C. He, S.-M. Wang, and J.-L. Zhang, "Landscape design of mountain highway tunnel portals in China," Tunnelling and Underground Space Technology, vol. 29, pp. 52-68, 2012.

[3] J. Lai, J. Qiu, J. Chen, H. Fan, and K. Wang, "New technology and experimental study on snow-melting heated pavement system in tunnel portal," Advances in Materials Science and Engineering, vol. 2015, Article ID 706536, 11 pages, 2015.

[4] J. A. Richards, "Inspection, maintenance and repair of tunnels: international lessons and practice," Tunnelling and Underground Space Technology, vol. 13, no. 4, pp. 369-375, 1998.

[5] H. Mashimo, N. Isago, T. Kitani, and T. Endou, "Effect of fiber reinforced concrete on shrinkage crack of tunnel lining," Tunnelling and Underground Space Technology, vol. 21, no. 3-4, pp. 382-383, 2006.

[6] B. Chiaia, A. P. Fantilli, and P. Vallini, "Evaluation of crack width in FRC structures and application to tunnel linings," Materials and Structures, vol. 42, no. 3, pp. 339-351, 2009.
[7] V. K. Ksenofontov, V. M. Mostkov, L. M. Pukhonto, and Y. E. Khechinov, "Minimum steel percent of hydraulic pressure tunnel linings," Hydrotechnical Construction, vol. 27, no. 1, pp. 15-24, 1993.

[8] T. Asakura and Y. Kojima, "Tunnel maintenance in Japan," Tunnelling and Underground Space Technology, vol. 18, no. 2-3, pp. 161-169, 2003.

[9] J. S. Lee, I.-Y. Choi, H.-U. Lee, and H.-H. Lee, "Damage identification of a tunnel liner based on deformation data," Tunnelling and Underground Space Technology, vol. 20, no. 1, pp. 73-80, 2005.

[10] R. Felicetti, “The drilling resistance test for the assessment of fire damaged concrete," Cement and Concrete Composites, vol. 28, no. 4, pp. 321-329, 2006.

[11] M. A. Meguid and H. K. Dang, "The effect of erosion voids on existing tunnel linings," Tunnelling and Underground Space Technology, vol. 24, no. 3, pp. 278-286, 2009.

[12] J. J. Lee, Y. Fukuda, M. Shinozuka, S. Cho, and C.-B. Yun, "Development and application of a vision-based displacement measurement system for structural health monitoring of civil structures," Smart Structures and Systems, vol. 3, no. 3, pp. 373384, 2007.

[13] J.-J. Lee, H.-N. Ho, and J.-H. Lee, "A vision-based dynamic rotational angle measurement system for large civil structures," Sensors (Switzerland), vol. 12, no. 6, pp. 7326-7336, 2012.

[14] X.-H. Li, H.-T. Wang, J.-Q. Jia, C.-H. Yang, G.-Z. Hu, and Z.$\mathrm{X}$. Xue, "Ultimate displacement discrimination of stability and reliability analysis of surrounding rocks of tunnel and underground engineering," Yantu Lixue/Rock and Soil Mechanics, vol. 26, no. 6, pp. 850-854, 2005.

[15] X. Luo and C. C. Xia, "Current situation and problems of classification of tunnel diseases," Chinese Journal of Underground Space and Engineering, vol. 2, no. 5, pp. 877-880, 2006.

[16] B. Zhou, X. Xie, and Y. Li, "A structural health assessment method for shield tunnels based on torsional wave speed," Science China Technological Sciences, vol. 57, no. 6, pp. 1109-1120, 2014.

[17] L. Feng, X. H. Yi, D. P. Zhu, X. Y. Xie, and Y. Wang, "Damage detection of metro tunnel structure through transmissibility function and cross correlation analysis using local excitation and measurement," Mechanical Systems and Signal Processing, vol. 60-61, pp. 59-74, 2015.

[18] W. L. Wang, T. T. Wang, J. J. Su, C. H. Lin, C. R. Seng, and T. H. Huang, "Assessment of damage in mountain tunnels due to the Taiwan Chi-Chi Earthquake," Tunnelling and Underground Space Technology, vol. 16, no. 3, pp. 133-150, 2001.

[19] P.-Y. Jeannin, A. Malard, D. Rickerl, and E. Weber, "Assessing karst-hydraulic hazards in tunneling-the Brunnmühle spring system-Bernese Jura, Switzerland," Environmental Earth Sciences, vol. 74, no. 12, pp. 7655-7670, 2015.

[20] L. Zhang, X. Wu, Q. Chen, M. J. Skibniewski, and J. Zhong, "Developing a cloud model based risk assessment methodology for tunnel-induced damage to existing pipelines," Stochastic Environmental Research and Risk Assessment, vol. 29, no. 2, pp. 513-526, 2015.

[21] J.-J. Lee, J.-M. Kim, S.-S. Ahn, and J.-S. Choi, "Development of a cable exciter to evaluate damping ratios of a stay cable," KSCE Journal of Civil Engineering, vol. 14, no. 3, pp. 363-370, 2010.

[22] T. A. Stabile, A. Giocoli, A. Perrone, A. Palombo, S. Pascucci, and S. Pignatti, "A new joint application of non-invasive remote sensing techniques for structural health monitoring," Journal of Geophysics and Engineering, vol. 9, no. 4, pp. S53-S63, 2012. 
[23] M. Proto, M. Bavusi, R. Bernini et al., "Transport infrastructure surveillance and monitoring by electromagnetic sensing: the ISTIMES project," Sensors, vol. 10, no. 12, pp. 10620-10639, 2010.

[24] Z. P. Nie, S. H. Zhu, W. G. Zhao, J. J. Pan, and Y. H. Tan, "Disease analysis and safety evaluation of a highway tunnel group," Journal of Huazhong University of Science and Technology (Urban Science Edition), vol. 20, no. 3, pp. 42-45, 2003.

[25] J. Lai, S. Mao, J. Qiu et al., "Investigation progresses and applications of fractional derivative model in geotechnical engineering," Mathematical Problems in Engineering, vol. 2016, Article ID 9183296, 15 pages, 2016.

[26] F. Kang, F. Qi, S. He, and B. Jiang, "Application of ground penetrating radar to disease detection of Kunlun Mountain tunnel," Chinese Journal of Rock Mechanics and Engineering, vol. 29, no. 2, pp. 3641-3646, 2010.

[27] Q. X. Yan, J. Zheng, J. Liu, and Y. J. Liu, "Disease detection and safety evaluation of Raglining highway tunnel," Highway, no. 6, pp. 228-233, 2010.

[28] F. Ye, C. He, and Y. X. Xia, "Post-construction monitoring and analysis for highway tunnel lining cracks," China Civil Engineering Journal, vol. 43, no. 7, pp. 97-104, 2010.

[29] J. Lai, H. Fan, J. Chen, J. Qiu, and K. Wang, "Blasting vibration monitoring of undercrossing railway tunnel using wireless sensor network," International Journal of Distributed Sensor Networks, vol. 2015, Article ID 703980, 7 pages, 2015.

[30] J. Lai, J. Qiu, Z. Feng, J. Chen, and H. Fan, "Prediction of soil deformation in tunnelling using artificial neural networks," Computational Intelligence and Neuroscience, vol. 2016, Article ID 6708183, 16 pages, 2016.

[31] Y. Luo, J. Chen, W. Xi et al., "Analysis of tunnel displacement accuracy with total station," Measurement: Journal of the International Measurement Confederation, vol. 83, pp. 29-37, 2016.

[32] J. Lai, K. Wang, J. Qiu, F. Niu, J. Wang, and J. Chen, "Vibration response characteristics of the cross tunnel structure," Shock and Vibration, vol. 2016, Article ID 9524206, 2016.

[33] B. Y. Lee, Y. Y. Kim, S.-T. Yi, and J.-K. Kim, "Automated image processing technique for detecting and analysing concrete surface cracks," Structure and Infrastructure Engineering, vol. 9, no. 6, pp. 567-577, 2013.

[34] M. Fan, D. K. Yi, and Z. M. Xiao, "Elastic-plastic stress investigation for an arc-shaped interface crack in composite material," International Journal of Mechanical Sciences, vol. 83, pp. 104-111, 2014.

[35] M. Fan, D. K. Yi, and Z. M. Xiao, "An interfacial arc-shaped Zener-Stroh crack due to inclusion-matrix debonding in composites," Acta Mechanica, vol. 225, no. 3, pp. 909-918, 2014.

[36] Z. Zhu, S. German, and I. Brilakis, "Visual retrieval of concrete crack properties for automated post-earthquake structural safety evaluation," Automation in Construction, vol. 20, no. 7, pp. 874-883, 2011.

[37] Y. Luo, J. Chen, P. Huang, M. Tang, X. Qiao, and Q. Liu, "Deformation and mechanical model of temporary support sidewall in tunnel cutting partial section," Tunnelling and Underground Space Technology, vol. 61, pp. 40-49, 2017.

[38] D. Diamantidis, F. Zuccarelli, and A. Westhäuser, "Safety of long railway tunnels," Reliability Engineering and System Safety, vol. 67, no. 2, pp. 135-145, 2000.

[39] J. Sanchez, J. Fullea, C. Andrade, and C. Alonso, "Stress corrosion cracking mechanism of prestressing steels in bicarbonate solutions," Corrosion Science, vol. 49, no. 11, pp. 4069-4080, 2007.
[40] W. Xue, L. Wang, D. Wang, and C. Druta, "Pavement health monitoring system based on an embedded sensing network," Journal of Materials in Civil Engineering, vol. 26, no. 10, 2014.

[41] A. Loizos and C. Plati, "Accuracy of pavement thicknesses estimation using different ground penetrating radar analysis approaches," NDT \& E International, vol. 40, no. 2, pp. 147-157, 2007.

[42] P. Holub, "Detection of cavities with the aid of electric measurements and ground-probing radar in a water-delivery tunnel," Journal of Applied Geophysics, vol. 31, no. 4, pp. 185-195, 1994.

[43] E. Cardarelli, C. Marrone, and L. Orlando, "Evaluation of tunnel stability using integrated geophysical methods," Journal of Applied Geophysics, vol. 52, no. 2-3, pp. 93-102, 2003.

[44] J. Lai, J. Qiu, H. Fan et al., "Fiber bragg grating sensors-based in situ monitoring and safety assessment of loess tunnel," Journal of Sensors, vol. 2016, Article ID 8658290, 10 pages, 2016.

[45] J. X. Lai, X. L. Wang, J. L. Qiu et al., "A state-of-the-art review of sustainable energy based freeze proof technology for coldregion tunnels in China," Renewable and Sustainable Energy Reviews, In press.

[46] J. Lai, S. He, J. Qiu et al., "Characteristics of seismic disasters and aseismic measures of tunnels in Wenchuan earthquake," Environmental Earth Sciences, vol. 76, no. 2, article 94, 2017. 

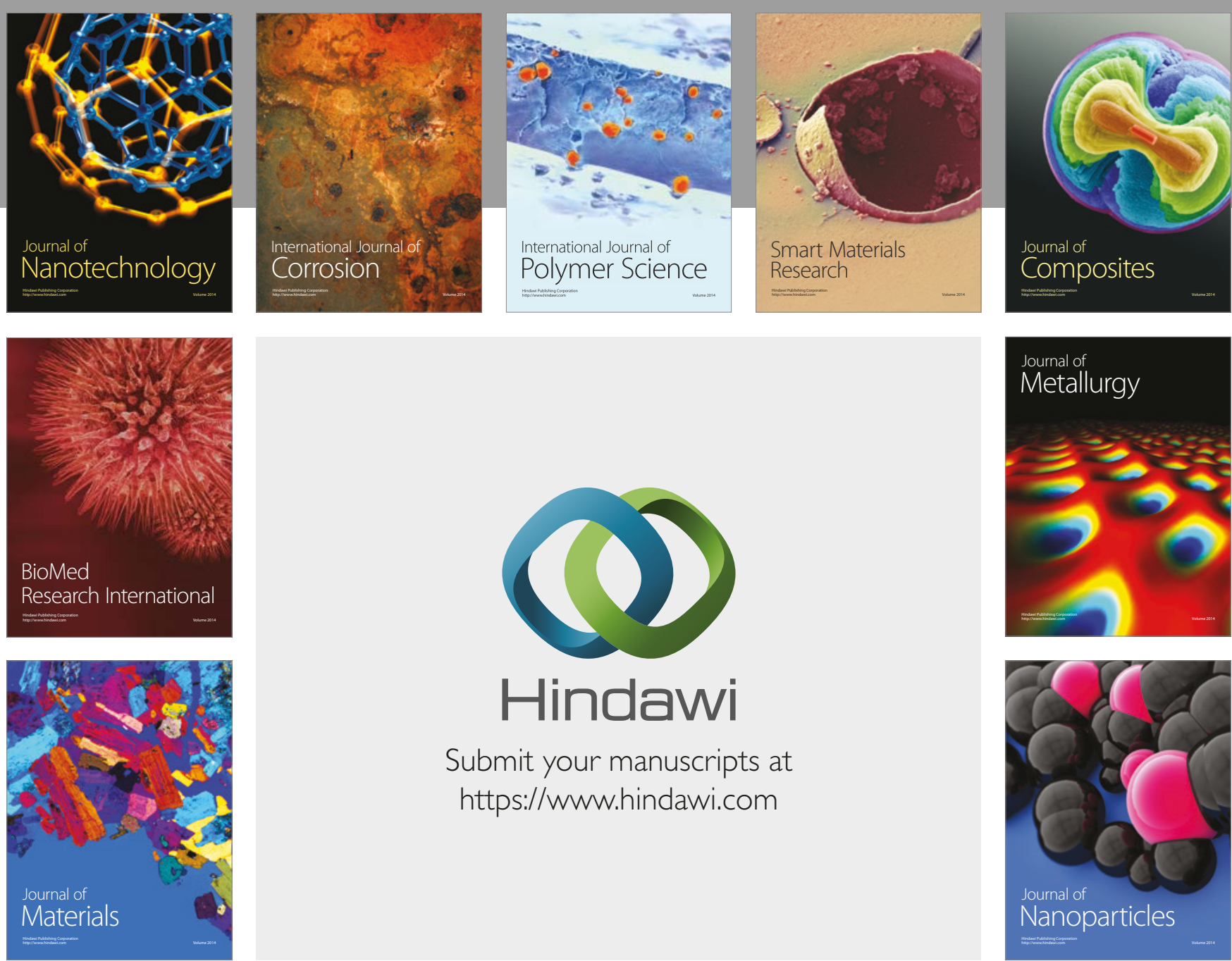

\section{Hindawi}

Submit your manuscripts at

https://www.hindawi.com
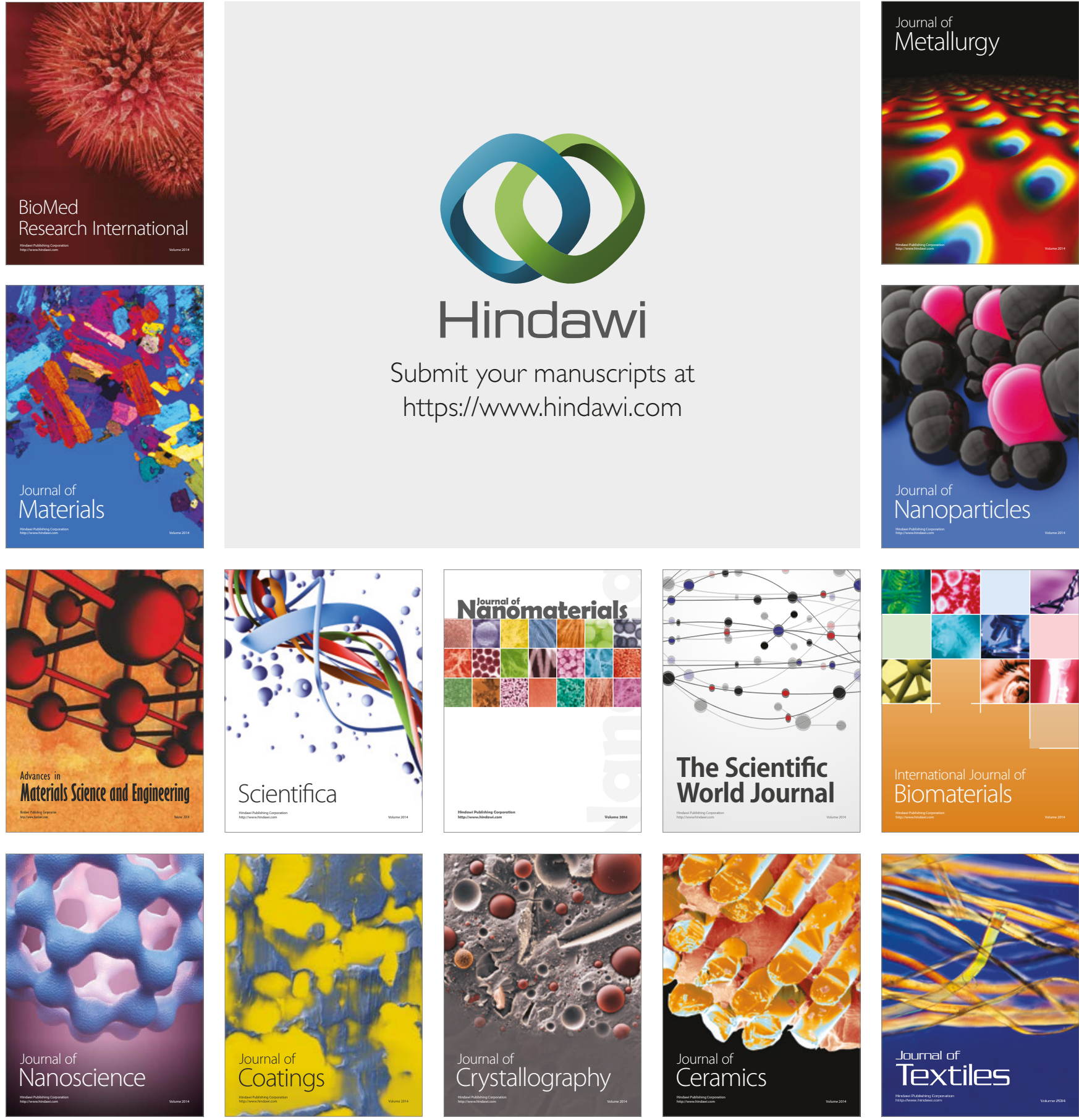

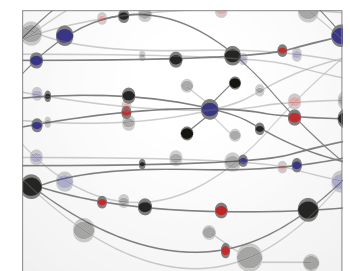

The Scientific World Journal
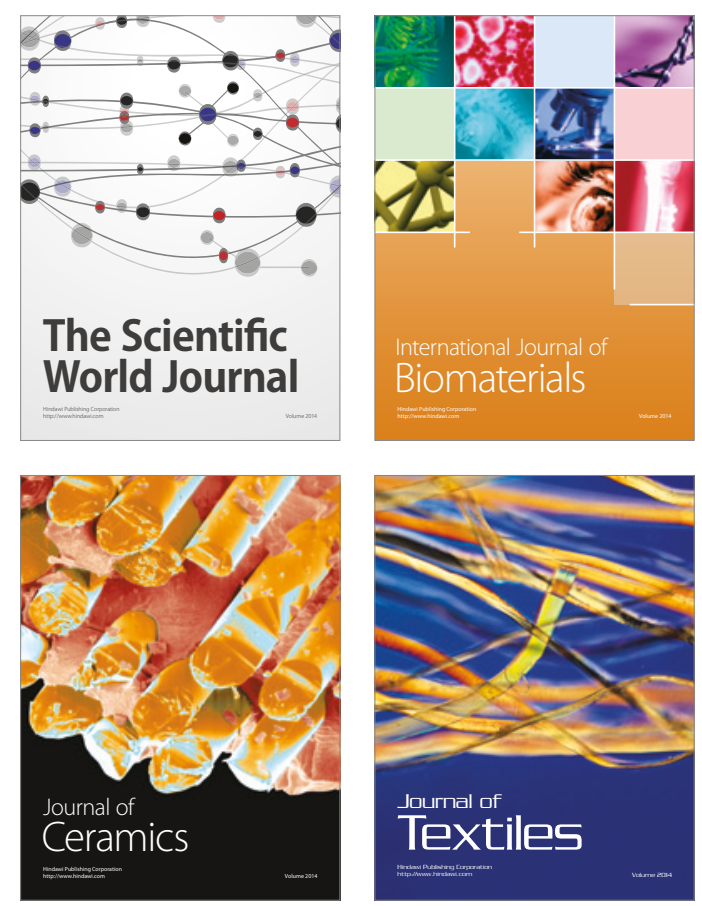